cardiovascular disease (CVD) mortality, which accounts for over $50 \%$ of premature deaths in RA. Obesity contributes to the development of inflammation via changes in metabolism and function of adipose tissue and it appears to coexist with other CVD risk factors such as hypertension, insulin resistance and dyslipidemia.

Objectives: For the first time, this study looks at the effect of the BMI on echocardiography parameters in established RA cases.

Methods: A cross section study was carried out to recruit patients meeting the 2010 ACR/EULAR criteria during 2019. Standard trans-thoracic echocardiography examination was performed by a specialist cardio-sonographer who was blinded to the status of the participants. The echocardiography parameters studied included left ventricular dimensions, wall geometry, systolic and diastolic parameters, ejection fraction, right ventricular size and function, valve structure and function, aortic root dimensions, pulmonary pressures and pericardium. Anthropometric measurements of BMI were carried out as weight in kilograms divided by the square of height in meters $\left(\mathrm{kg} / \mathrm{m}^{2}\right)$. Data was analysed using the $\mathrm{BMI}$ as the explanatory variable and repeating the simple linear regression analysis using the echocardiography parameters as outcome variables. $P$ value of $<0.05$ was considered significant.

Results: During the one-year period, 44 RA patients were recruited, of which $91 \%$ (40) were female and 4 (9\%) male. The mean (SD) of age was $50 \pm 13$ years (Min 28, Max 72). The mean (SD) of BMI was $30.887 \pm 6.348 \mathrm{Kg} / \mathrm{m}^{2}$ (Min 21, Max 44.38). As per BMI classification of obesity, only $11 \%$ patients were found to have normal BMI. Echocardiography revealed that $14 \%$ patients had aortic regurgitation, $2 \%$ had aortic stenosis, $2 \%$ had mitral stenosis, and $7 \%$ had tricuspid regurgitation.

Using BMI as an explanatory variable, with echocardiography parameters as outcome variables, it was found that BMI contributed positively in a linear manner to the Interventricular Septal thickness in diastole $(\mathrm{mm})(\mathrm{p}=0.004, \mathrm{Cl}: 0.048-0.227)$, LV End Diastolic Diameter $(\mathrm{mm})(\mathrm{p}=0.033, \mathrm{Cl}$ : 0.033-0.722), LV mass $(\mathrm{g})(0.04$, $\mathrm{Cl}$ : 0.022-6.339), Early Diastolic Velocity, E, by PW mitral inflow measurement $(\mathrm{cm} / \mathrm{s})(\mathrm{p}=0.02, \mathrm{Cl}: 0.150-1.933)$, E/E' ratio by Tissue Doppler study $(\mathrm{p}=0.01$, $\mathrm{Cl}: 0.025-0.225$ ), and to Right Ventricle function measured by Tricuspid Annular Plane Systolic Excursion (TAPSE) (mm) $(p=0.02, \mathrm{Cl}$ : 0.035-0.346).

Conclusion: Obesity and Inflammation overlap syndrome may interplay to produce various cardiovascular abnormalities. Body Mass Index is shown to be associated with significant echocardiographic abnormalities including left ventricular dimension, diastolic parameters and right ventricular function. In view of the complex interrelation between obesity, rheumatoid arthritis and cardiovascular disease, measuring Body Mass Index might help predict adverse cardiovascular events in rheumatoid arthritis patients.

REFERENCES:

[1] Body mass index and the risk of rheumatoid arthritis: a systematic review and dose-response meta-analysis. Qin B, Yang M, Fu H, Ma N, Wei T, Tang Q, Hu Z, Liang Y, Yang Z, Zhong R. Arthritis Res Ther. 2015; 17(1): 86. doi: 10.1186/s13075-015-0601-X.

[2] Cardiac eccentric remodeling in patients with rheumatoid arthritis. Pascale V, Finelli R, Giannotti R, Coscioni E, Izzo R, Rozza F, Caputo D, Moscato P, laccarino G, Ciccarelli M. Sci Rep. 2018; 8: 5867. doi: 10.1038/ s41598-018-24323-0.

Disclosure of Interests: None declared

DOI: 10.1136/annrheumdis-2021-eular.3125

\section{AB0169 \\ INTEREST OF THE ECHOCARDIOGRAPHY IN SCREENING OF CARDIAC INVOLVEMENT IN RHEUMATOID ARTHRITIS PATIENTS}

M. Brahem ${ }^{1}$, H. Ibn Hadj Amor ${ }^{2}$, R. Sarraj ${ }^{1}$, R. Rouabhia ${ }^{2}$, E. Hmaier ${ }^{2}$, H. Hachfi ${ }^{1}$, A. Ben Salem ${ }^{1}$, S. Abdellatif ${ }^{1}$, R. Ben Tekaya ${ }^{1}$, Y. Mohamed ${ }^{1} .{ }^{1}$ Taher Sfar Hospital, Rheumatology, Mahdia, Tunisia; ${ }^{2}$ Taher Sfar Hospital, Cardiology, Mahdia, Tunisia

Background: Rheumatoid arthritis (RA) is the most common chronic inflammatory disease which usually affects peripheral joints. Extra-articular manifestations can occur during the course of this disease and even before the onset of arthritis, such as cardiac impairment that is a common cause of mortality in RA.

Objectives: The aim of our study is to identify the prevalence of cardiac manifestations in RA using the echocardiography exam and to elaborate its associated factors.

Methods: This is a cross-sectional study including consecutive RA's patients which consulted the rheumatology department in Taher Sfar hospital. The diagnosis of RA was elaborate according to ACR/EULAR 2010 criteria. The epidemiological, clinical and biological data were collected from patients' records. Echocardiography was performed by a trained cardiologist in the same hospital, using the transthoracic approach.

Results: Our study included 67 patients: 63 women (94\%) and 4 men (6\%), with an average age of 52.55 years [21-75 years] and mean disease duration of 11.85 years [10-40]. Joints deformities were present in 37 cases $(55.2 \%)$ and radiographic joint damage in 49 cases $(73.1 \%) .34(50.7 \%)$ of the patients had an ESR greater than $30 \mathrm{~mm} /$ hour and $24(35.8 \%)$ had a CRP greater than $6 \mathrm{mg} / \mathrm{L}$. The mean DAS28-CRP was 3.35 [1.24-6.7] and the mean DAS28-ESR was 4 [1.4-7.35]. Cardiac symptomatology was present in 22 cases (32.8\%), dominated by dyspnea on effort in 22 cases $(32.8 \%)$, dyspnea at rest in 4 cases $(6 \%)$ chest pain in 8 cases (11.9\%)and palpitation in 2 cases $(3 \%)$. The echocardiography abnormalities were found in 44 cases. Valve damage was detected in 35 patients $(52.2 \%)$, of which only 2 were significant. Valvular abnormalities were dominated by mitral valve regurgitation and mitral valve thickening in 11 cases (16.4\%) each, aortic valve regurgitation in 6 cases (9\%), aortic valve thickening in 2 cases (3\%), aortic valve stenosis in 3 cases (4.5\%), aortic valve calcification in 12 cases $(17.9 \%)$ aortic valve nodule in 1 case $(1.5 \%)$, pulmonary insufficiency in 10 cases $(14.9 \%)$ and tricuspid insufficiency in 25 cases $(37.3 \%)$. Pericarditis was found in 2 cases (3\%), pulmonary arterial hypertension (PAH) in 5 cases $(7,5 \%)$ and Left ventricular hypertrophy in 14 cases $(20,9 \%)$. The study of E/A and $E / E$ ' ratios revealed diastolic dysfunction in 23 cases $(34.3 \%)$. The mean of longitudinal global strain measure was $-17,83$ [-21,9 to -10] and it revealed sys tolic dysfunction in 18 cases $(26.86 \%)$. Cardiac impairment detected by echocar diography did not appear to be associated with the age $(p=0.39)$ or the disease duration $(p=0.62)$ nor the importance of biological inflammation $(p=0.1)$. However joints deformities and RA activity (DAS28) were significant predictors of cardiac involvement $(p=0.01 ; p=0.03)$.

Conclusion: Our study shows that cardiac impairment in RA was often asymptomatic and was correlated with the disease activity. The echocardiography with the strain measure represents an excellent tool for its detection in early stages. REFERENCES:

[1] Guedes C, Bianchi-Fior P, Cormier B, Barthelemy B, Rat AC, Boissier MC. Cardiac manifestations of rheumatoid arthritis: A case-control transesophageal echocardiography study in 30 patients. Arthritis Care Res. 2001;45(2):129-35.

Disclosure of Interests: None declared

DOI: 10.1136/annrheumdis-2021-eular.3128

\begin{tabular}{l|l}
\hline AB0170 & RHEUMATOID ARTHRITIS ASSOCIATED LUNG \\
DISEASE: EXPERIENCE IN A BIOLOGICAL THERAPY \\
UNIT
\end{tabular}

L. Vega ${ }^{1}$, I. Calvo ${ }^{2}$, O. Ibarguengoitia ${ }^{2}$, D. Montero ${ }^{1}$, C. García ${ }^{1}$, E. Galindez ${ }^{1}$, J. M. Blanco ${ }^{1}$, A. R. Intxaurbe ${ }^{1}$, I. Torre ${ }^{1}$, C. E. Perez ${ }^{1}$, O. Fernandez ${ }^{1}$, E. Cuande ${ }^{1}$ M. R. Exposito-Molinero ${ }^{1}$, E. Guerrero ${ }^{3}$, M. L. García Vivar ${ }^{1}$, M. E. Ruiz ${ }^{1}$. ${ }^{1}$ Basurto University Hospital, Rheumatology Unit, Bilbao, Spain; ${ }^{2}$ Galdakao University Hospital, Rheumatology Unit, Galdakao, Spain; ${ }^{3}$ Alto Deba Hospital, Rheumatology Unit, Arrasate, Spain

Background: Rheumatoid arthritis (RA) associated lung disease is a relatively frequent extra articular disease manifestation, with a prevalence between $5 \%$ and $30 \%$. The rather wide range of estimated prevalence is a result of differences in study designs and studied populations, as well as lacking diagnostic and classification criteria for lung disease in patients with RA.

Objectives: To evaluate the prevalence of RA associated lung disease in patients with biological therapy (BT), as well as its severity, treatment changes and possible associated factors.

Methods: Review of clinical records of 257 patients with RA treated with BT (TNFi, non-TNFi) between January 2015 to December 2020 in a single center. Patients with preexisting lung disease for other causes (asthma, smoking) have been excluded. RA diagnosis was performed according to ACR 2010 classification criteria. Epidemiological variables, clinical characteristics, type of pulmonary involvement, evolution, type of BT, changes in treatment and concomitant treatment were collected. For the analysis frequencies and percentages are used in qualitative variables, and mean $\pm S D$ in the quantitative ones. Statistical analysis was performed with IBM SPSS v 23.

Results: We registered 21 patients ( $85.7 \%$ women) mean aged $70.3 \pm 11.9$ years $52.4 \%$ were never smokers. RF was positive in $100 \%$ and 20 patients were antiCCP positive. Erosive disease was present in 13 (61.9\%) patients.

At the time of lung disease diagnosis, 15 patients $(66.7 \%)$ were receiving TNF (Etanercept 7, Adalimumab 6, Infliximab 1, Golimumab 1), 2 were with non-TNFi (Rituximab) and 4 had never received BT previously. Symptoms (cough and/or dyspnea) were reported in $10(47.6 \%)$ patients. The median time of treatment with BT until lung disease diagnosis was 33 [15.5-95.5] months. Conventional synthetic DMARDs (csDMARDs) were used in $85.7 \%$ of cases (methotrexate $72.2 \%$, leflunomide $22.2 \%$, other $5.6 \%$ ). The inflammatory activity was mild (DAS28: 3.22 \pm 1.6$)$. The median time until lung disease diagnosis was 104 [56.2156] months.

After the lung disease diagnosis, BT was only modified in 1 patient. In the 4 patients who had not previously received BT, non-TNFi was started (Rituximab 2 , Abatacept 1, Tocilizumab 1). csDMARD was discontinued in 1 patient. Interstitial lung disease (ILD) was the most frequent pulmonary involvement (16 patients, 76.2\%): 8 usual interstitial pneumonia (UIP), 6 non-specific interstitia 